\title{
Effectiveness of Carbon Electrode Electrolysis Effluent Treatment System in Textile Dyeing
}

\author{
Md. Mahbubur Rahman ${ }^{1}$, Mohammad Forhad Hossain ${ }^{2}$ and Mustafijur Rahman ${ }^{2 *}$ \\ ${ }^{1}$ Bangladesh Jute Research Institute, Bangladesh \\ ${ }^{2}$ Department of Dyes and Chemicals Engineering, Bangladesh University of Textiles, Bangladesh
}

*Corresponding author: Mustafijur Rahman, Department of Dyes and Chemicals Engineering, Bangladesh University of Textiles, Dhaka, Bangladesh.

https://orcid.org/0000-0001-8411-0933
Received Date: March 12, 2021

Published Date: June 01, 2021

\begin{abstract}
The electrolysis process is an easy alternative for the treatment of textile dyehouse wastewater. To study the effectiveness of the carbon electrode electrolysis method in dyehouse effluent treatment is the main objective of this research. In most cases, the metal electrode used in the electrolysis system becomes decayed and needs to be replaced after a certain time. In this study, an inert carbon electrode has been chosen to treat the cotton dyehouse wastewater that can function longer than a metal electrode. Hence, the process is named as Carbon Electrode Electrolysis (CEE) method. In this method, a combined effect of electro-coagulation and electro-reduction has occurred. Electro-coagulation happens by direct charge supplied from a carbon electrode and then neutralizing negative effluent charges using positive charge. The color chromophore becomes broken down by a reduction in the cathode. Through electrolysis of sodium chloride in the effluent, sodium hypochlorite is produced, which later oxidizes organic compounds and reduces BOD. The effects of different treatment parameters of the CEE method like salt concentration and operating time have been studied and found that higher salt concentration and around 65 minutes operating time is effective. The results are analyzed based on four criteria: Color change, Biological Oxygen Demand (BOD), Chemical Oxygen Demand (COD) and Total Dissolved Solids (TDS). Results show that the CEE method minimizes effluents' color and reduces BOD and COD within the acceptable limits of the Department of Environment (DoE), Bangladesh. Moreover, the CEE Effluent Treatment Plant (ETP) needs less space than the other existing biological and chemical ETP. However, this method is failed to remove TDS from wastewater.
\end{abstract}

Keywords: Textile effluents; Carbon electrode electrolysis; Coagulation; Flocculation; Oxidation

\section{Introduction}

Textile dyeing is a necessary wet chemical process to finish textile goods in different forms. Textile dyehouse consumes a huge amount of water for chemical treatment and washing of textile materials. One Kilogram of the material requires about $150 \mathrm{~L}$ of water [1]. Around $40 \%$ water is used in pretreatment and $25 \%$ for dyeing and printing [2]. Estimation of 1000-3000 $\mathrm{m}^{3}$ of wastewater is produced after processing 12-20 tons of textiles [3]. Scouring and mercerizing processes use maximum water in pretreatment [1]. Among various dyes, sulphur and reactive dyes' fixation to Fibre is poor and come out with effluent in a large amount [4].

Textile wastewater increases the effluent load by increasing organic materials and decreasing available dissolved oxygen.
Pretreatment processes such as scouring and bleaching release more effluents than dyeing. With respect to BOD, Desizing bears $30-50 \%$ load, scouring 30\%, bleaching 5\%, mercerizing 1\%, dyeing $6 \%$, printing $20 \%$ [5]. About $15 \%$ of total dyes are lost during processing [6]. Basic and acid dyes exhaust most, and Sulphur and reactive dyes show poor exhaustion and become lost in effluent [6]. The azo chromophore is more dangerous than anthraquinone as azo can change to toxic amino acids [7]. Basic and diazo dye shows maximum toxicity. Dyes can interact with the photosynthetic system in water life [8].

During preliminary treatment of effluents, suspended solids, oils and grease, gritty materials are removed [9]. At first, large 
suspended materials like yarns, parts of the fabric, Fibres, rags are screened using a bar and fine screens [10]. Then sedimentation is done to settle suspended particles like clay or slits. Neutralization is done using $\mathrm{NaOH}$ or $\mathrm{H}_{2} \mathrm{SO}_{4}$. To increase efficiency and to remove colloidal particles, chemical coagulation is required [10]. Ferrous sulphate, lime, alum, ferric sulphate, and ferric chloride are common coagulants [11]. In secondary treatment, BOD load is reduced from dissolved organic matter by converting these matters into $\mathrm{CO}_{2}$, water and ammonia by oxidation of aerobic or anaerobic bacteria. This can be achieved by aerated lagoons, trickling filters and aerobic activated sludge system. The aerated lagoon is just a holding tank with airflow to allow oxidation by natural microorganisms, but it is time-consuming and requires huge space [10]. In the trickling filtration method, the effluent is sprayed or trickled over a filter where a thick film made of micro-organisms has been formed. This system requires less space, but it is costly and emit a huge odor. The activated sludge method involves regular aeration of effluent to allow aerobic bacteria to metabolize organic matter to oxidize into $\mathrm{CO}_{2}$, and rests are synthesized into new microbial cells [12]. Some of the produced sludge is returned to the aeration tank as a source of microbes. About 90-95\% BOD removal is achieved by this process [13]. Then a tertiary treatment like electrolysis,

Table 1: Specification of effluent materials.

\begin{tabular}{|c|c|c|c|c|}
\hline Sample & COD & BOD & TDS & pH \\
\hline Sample 1 & 341 & 230 & 3450 & 11.5 \\
\hline Sample 2 & 320 & 210 & 3540 & 12 \\
\hline Sample 3 & 360 & 240 & 3220 & 11 \\
\hline Sample 4 & 365 & 225 & 3550 & 12 \\
\hline
\end{tabular}

\section{Methods}

Cotton dyeing wastewater contains a high amount of salt along with alkaline $\mathrm{pH}$. Sodium ( $\mathrm{Na}$ ) atom becomes free at the cathode and $\mathrm{Cl}_{2}$ gas at the anode by using a sodium chloride solution. The sodium immediately reacts with water and produces sodium hydroxide, and if the anode and cathode are sufficiently close to each other, the chlorine will react with sodium hydroxide, and the result will be a sodium hypochlorite solution. The temperature should not be over $50 \circ \mathrm{C}$. Otherwise, sodium chlorate will be formed instead of hypochlorite [23].

$$
\begin{aligned}
& \mathrm{Nacl} \rightarrow \mathrm{Na}^{+}+\mathrm{Cl}^{-} \\
& \mathrm{H}_{2} \mathrm{O} \rightarrow \mathrm{H}^{+}+\mathrm{OH}^{-}
\end{aligned}
$$

\section{Cathode Reaction}

$\mathrm{Na}^{+}+\mathrm{e}^{-} \rightarrow \mathrm{Na}$

$\mathrm{Na}+\mathrm{H}_{2} \mathrm{O} \rightarrow \mathrm{NaOH}$

Color Chromophore $+\mathrm{e}^{-}$-> Discolored color molecule

\section{Anode Reaction}

$$
2 \mathrm{Cl}^{-}-e^{-} \rightarrow \mathrm{Cl}_{2}
$$

reverse osmosis, ion exchange is done to reduce TDS value [14].

Electrolysis involves chemical change results from electron transfer reaction in electrode-solution interface by introducing a driving force from voltage source [15]. The electrochemical process can be used in an aqueous effluent treatment where no chemical addition is required. Here electrons, effluents, salt released from dyeing are only reactants. Electro-coagulation and electro-oxidation occur here. This process destructs toxic and non-biodegradable organics through direct or indirect oxidation and reduction $[16,17]$. To destroy the chromophoric group, the electrochemical process is effective [18-22]. An experimental trial was done at NITER Lab to minimize salts used in cotton dyeing by applying a direct charge on cotton through a carbon electrode. Then a huge amount of dye aggregation as a flock like substance was observed. The idea of using carbon electrode in effluent treatment was generated from this observation.

\section{Experimental}

\section{Materials}

Wastewater was collected from GMS Knit Composite Ltd, Kashimpur, Gazipur. Four effluent samples were collected. Their characterization is as follows (Table 1): 


\section{Results and Discussions}

\section{Qualitative analysis}

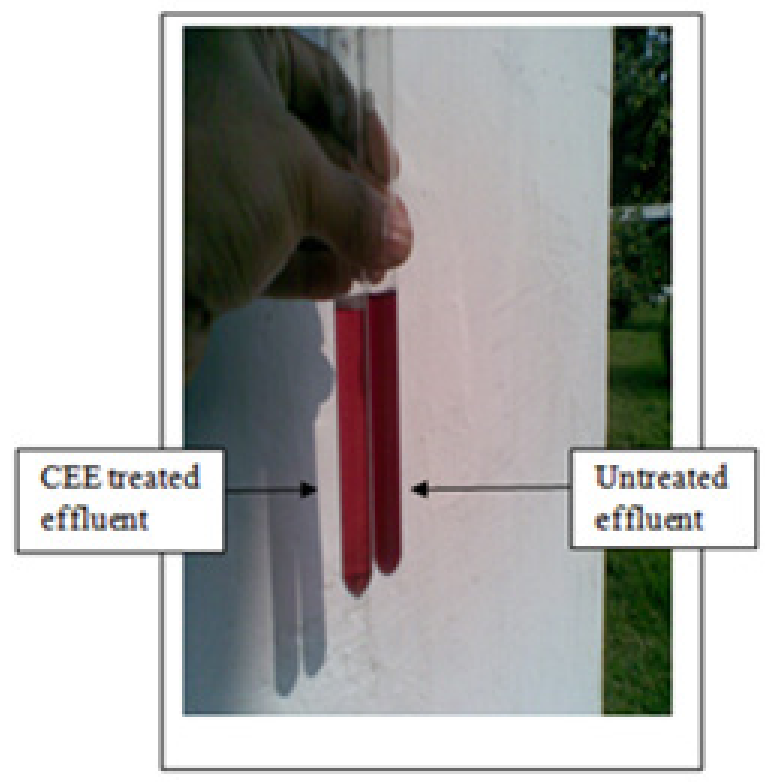

Figure 1: After 5 min electrolysis slight color change.

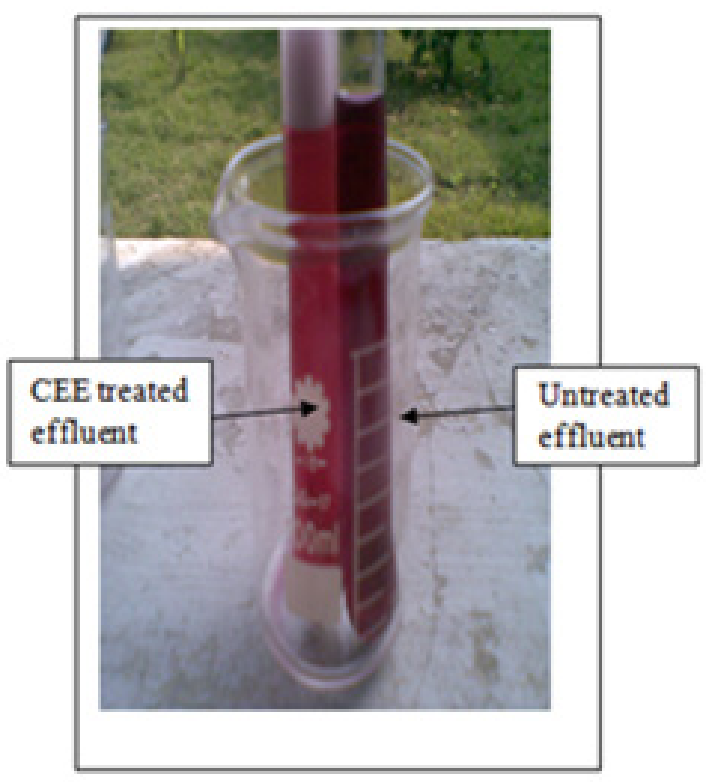

Figure 2: Reaction continues and after 20min a good color difference.

It is noticed that cathode produces a high amount of gas bubble with foam. Anode also produces gas babble but lower than the cathode (Figure 1). As discussed in theory, the produced gas in the anode is chlorine, and in the cathode, sodium hydroxide is formed. After 20 minutes of electricity passing, it seems good color change, as shown in Figure 2.

Then, $1 \mathrm{gm}$ salt is added. The reaction becomes intensified. After 28-minute a remarkable amount of shade variation is found as Figure 3. After $45 \mathrm{~min}$, significant shade variation is found, but the reaction is slower, as shown in Figure 4 . After $45 \mathrm{~min}$, $1 \mathrm{gm}$ salt is added.

After $55 \mathrm{~min}$, it is found that something reddish-violet is coagulating on the upper surface of the solution, as shown in Figure 5. Then $1 \mathrm{gm}$ salt is added more, and the reaction continues for 10 min. Finally, a Crystal-clear solution appears, as shown in Figure 6. 


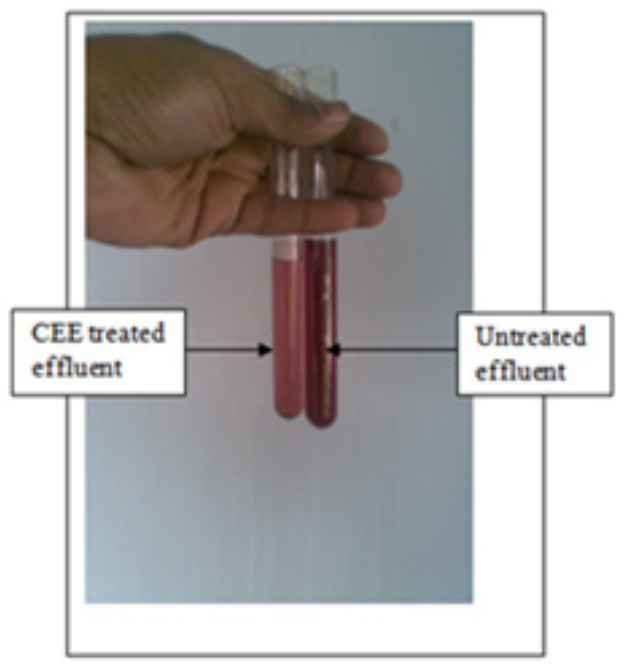

Figure 3: After 28 min remarkable color difference.

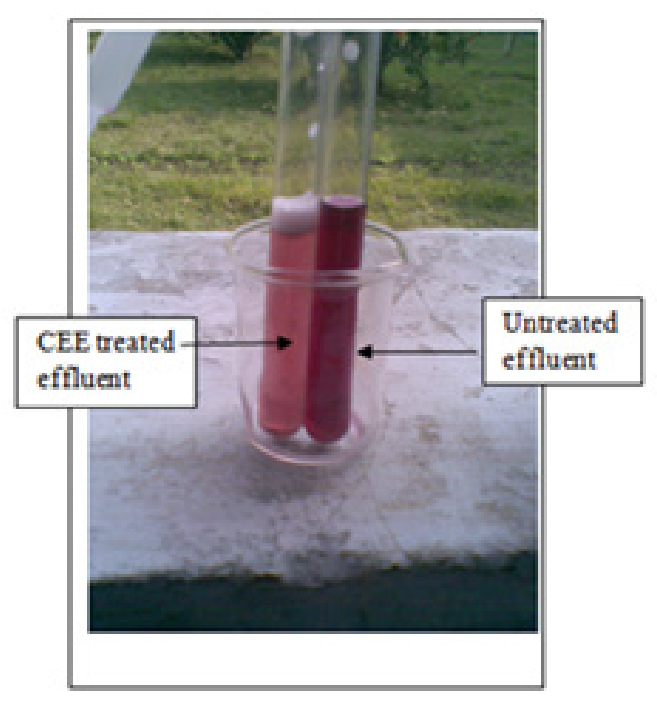

Figure 4: After 45 min significant removal of color.

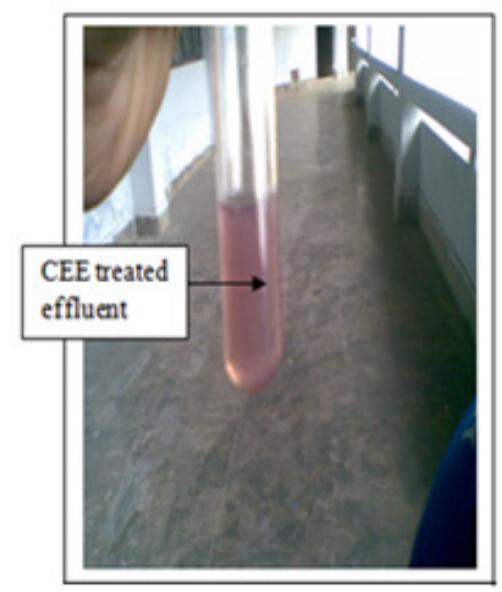

Figure 5: After 55 min some coagulant an upper surface. 


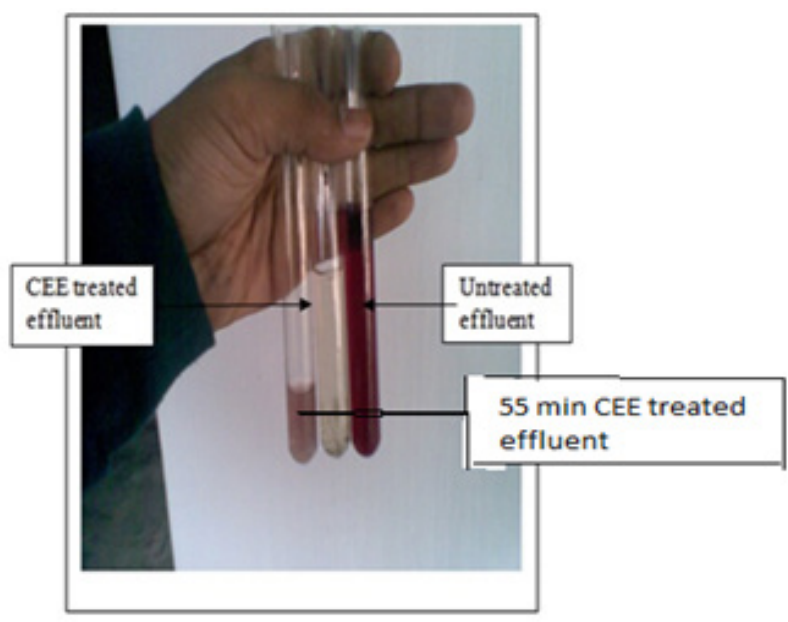

Figure 6: At last crystal-clear solution appears.

\section{Comparison between the solution before and after} electrolysis

The four effluent samples are treated following the CEE technique for 65 minutes. The effluent load reduction is within an acceptable range of DoE, Bangladesh, except the TDS load. The effect of treatment time effect on each COD test, BOD, and TDS is analyzed for four effluent samples in Table 2.

Table 2: Comparison of solution before and after CEE treatment.

\begin{tabular}{|c|c|c|c|c|c|c|c|c|}
\hline \multirow{2}{*}{ Sample } & \multicolumn{2}{|c|}{ COD(mg/L) } & \multicolumn{2}{c|}{ BOD5 (mg/L) } & \multicolumn{2}{c|}{ TDS (mg/L) } & \multicolumn{2}{c|}{ pH } \\
\cline { 2 - 10 } & Before & After & Before & After & Before & After & Before & After \\
\hline Sample 1 & 341 & 249 & 230 & 88 & 3450 & 3490 & 11.5 & 9 \\
\hline Sample 2 & 320 & 230 & 210 & 70 & 3540 & 3550 & 12 & 8.5 \\
\hline Sample 3 & 360 & 250 & 240 & 90 & 3220 & 3250 & 11 & 9 \\
\hline Sample 4 & 365 & 210 & 225 & 95 & 3550 & 3580 & 12 & 9 \\
\hline
\end{tabular}

\section{Chemical Oxygen Demand (COD) and Biological Oxygen Demand (BOD)}

Carbon electrode electrolysis treatment and chemical treatment with ferrous sulphate were investigated at different treatment time on the COD and BOD removal of textile industrial wastewater. Figures 7 and 8 show that COD and BOD removal percentage increase with the increase of treatment time. This is due to the production of an oxidant such as hypochlorite ion in solution. Increasing generation of oxidant is proportional to treatment time, which eventually increases the pollutant degradation.

From figure 7 and 8, it can be analyzed that BOD \& COD removal by carbon electrolysis is less than the chemical ETP, but the result is within the acceptable limit.

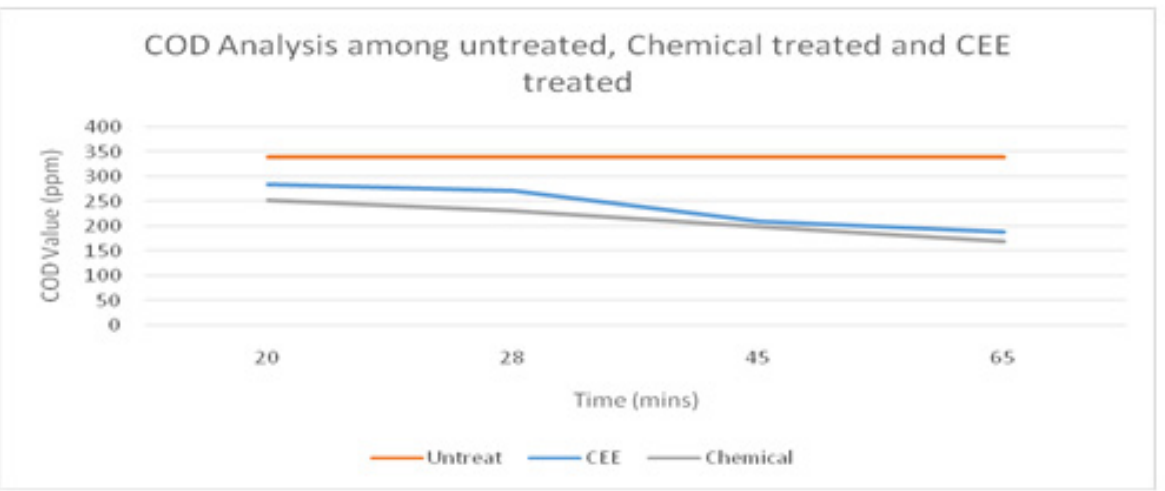

Figure 7: COD analysis among untreated, chemically treated, and CEE treated sample. 


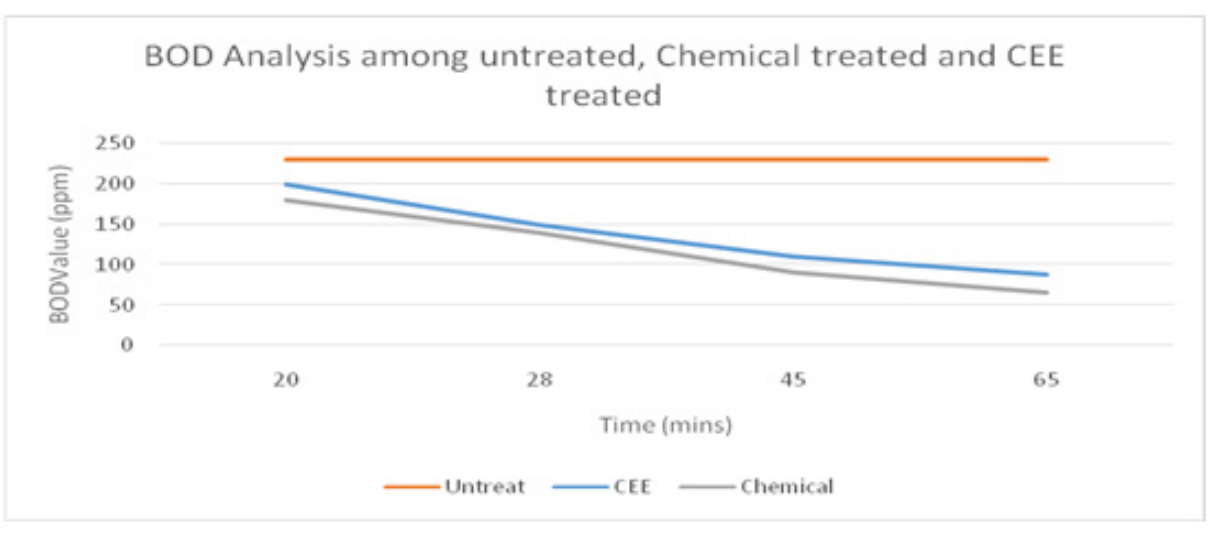

Figure 8: BOD analysis among untreated, chemical treated, and CEE treated samples.

\section{Total Dissolved Solid (TDS)}

From Figure 9, it is observed that in the CEE method, TDS is more or less equal than raw effluent by the CEE method but reduced by chemical effluent treatment. Higher TDS value is beneficial in CEE method it increases electrolyte concentration and thus increases electrolysis.

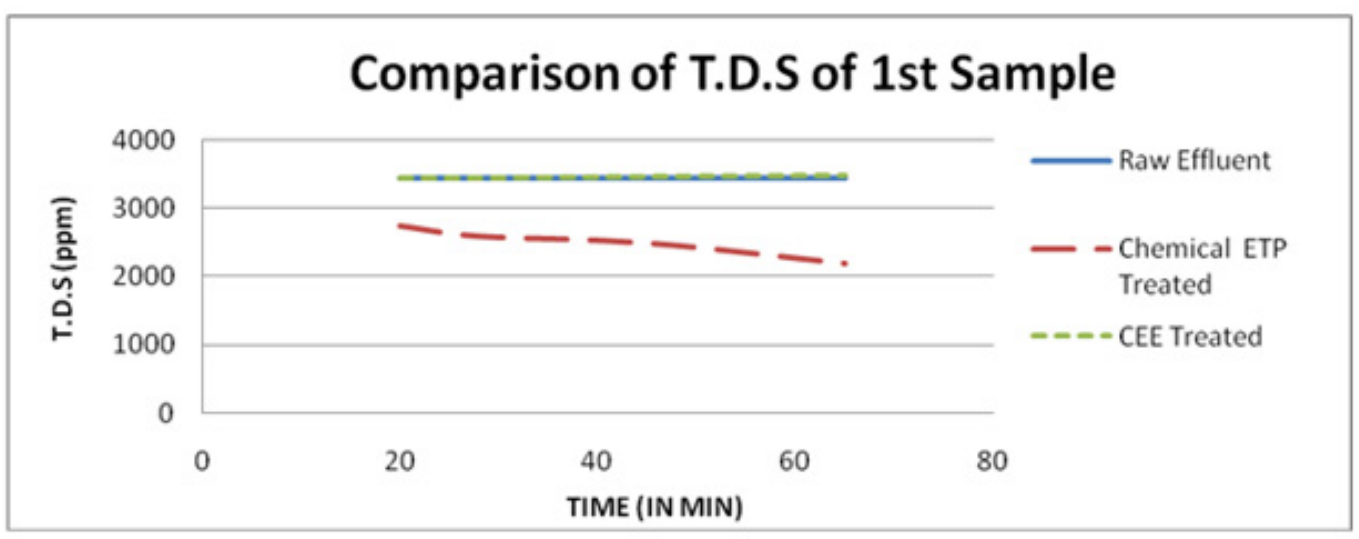

Figure 9: Comparison of TDS result between CEE treated sample and chemical ETP.

\section{Effect of electrolysis time}

The effect of electrolysis time on COD removal under the optimal conditions was investigated. The COD removal percentage rapidly increased with the increase of electrolysis time up to 65 minutes Figures 7 \& 8 . The COD removal efficiency depends directly on the concentration of electrochemically generated hypochlorite ion in the bulk solution. When the electrolysis time is longer, more hypochlorite ion is produced in solution under fixed current density. Therefore, color and COD value in the solution were reduced in a higher concentration of hypochlorite. The electrolysis time at 65 minutes is considered the optimal electrolysis time due to only a slight difference in COD removal percentage compared to further treatment.

\section{Effect of salt concentration}

The effluent was collected from a cotton dye house. So, the effluent inherently contained salt concentration. Moreover, added salt was used during experiment execution. Salt addition increased TDS value. The more the salt addition, the more efficiency of wastewater treatment obtained, as shown in Figure 10.

\section{Conclusion}

The research outcome is that the CEE method removes COD, BOD, and color of dyehouse effluent within an acceptable range according to the Direction of the Department of Environment, Bangladesh. The Investigation has shown that the CEE method removes organic effluent load by three mechanisms. One is charge neutralizing flocculation, and the others are electro-reduction and electro-oxidation. The major limitation of this research is the difficulty of TDS removal from dyehouse effluent. TDS cannot be removed within an acceptable range. Moreover, higher TDS value results in Moreover, a higher TDS value results in more removal of BOD and COD load. Investigation on the reduction of TDS is recommended for future research. 


\section{Acknowledgement}

None.

\section{Conflict of Interest}

Authors declare no conflict of interest.

\section{References}

1. Ntuli F, Omoregbe DI, Kuipa PK, Muzenda E, Belaid M (2009) Characterization of effluent from textile wet finishing operations. World Congress on Engineering and Computer Science.

2. Manu B, Chaudhari S (2003) Decolorization of indigo and azo dyes in semicontinuous reactors with long hydraulic retention time. Process biochemistry 38(8): 1213-1221.

3. Ghaly AE, Ananthashankar R, Alhattab MVVR, Ramakrishnan VV (2014) Production, characterization and treatment of textile effluents: a critical review. J Chem Eng Process Technol 5(1): 1-18.

4. Tehrani-Bagha AR, Mahmoodi NM, Menger FM (2010) Degradation of a persistent organic dye from colored textile wastewater by ozonation. Desalination 260(1-3): 34-38.

5. Laxman M (2009) Pollution and its control in textile industry. Dyes and Chemicals.

6. Easton JR (1995) The problem of color. Color in dye house effluent. Society of Dyers and Colourists, Bradford, England, 88s, pp.9-21.

7. Franco JH, da Silva BF, Dias EFG, de Castro AA, Ramalho TC, et al. (2018) Influence of auxochrome group in disperse dyes bearing azo groups as chromophore center in the biotransformation and molecular docking prediction by reductase enzyme: Implications and assessment for environmental toxicity of xenobiotics. Ecotoxicology and environmental safety 160: 114-126.

8. Waters BD (1995) Colour in Dyehouse Effluent. Ed. P. Cooper, Society of Dyers and Colourists, Bradford, p.22.

9. Eswaramoorthi S, Dhanapal K, Chauhan D (2008) Advanced in textile waste water treatment: the case for UV-ozonation and membrane bioreactor for common effluent treatment plants in Tirupur, Tamil Nadu, India. Environmental technology awareness series, pp.1-17.
10. Das S (2000) Textile Effluent Treatment-A Solution to the Environmental Pollution. Fibre2Fashion: Ahmedabad, India

11. Chen X, Shen Z, Zhu X, Fan Y, Wang W (2005) Advanced treatment of textile wastewater for reuse using electrochemical oxidation and membrane filtration. Water SA 31(1): 127-132.

12. Mathuram WD (2003) Computer aided management of processes (CAMP) at the National Environmental Service Center. West Virginia University, USA.

13. Yasui H, Nakamura K, Sakuma S, Iwasaki M, Sakai Y (1996) A full-scale operation of a novel activated sludge process without excess sludge production. Water Science and Technology 34(3-4): 395-404.

14. Kannan MSS, Gobalakrishnan M, Kumaravel S, Nithyanadan R, Rajashankar KJ, Vadicherala T (2006) Influence of cationization of cotton on reactive dyeing. Journal of Textile and Apparel, Technology and Management 5(2): 1-16.

15. Electrolysis I. An Introduction to the Electrochemical Reaction.

16. Rajeshwar K, Ibanez JG (1997) Fundamentals and application in pollution abatement. In Environmental Electrochemistry (pp. 127-138). Academic Press San Diego, USA.

17. Fanton JM (1994) Electrochemistry: energy, environment, efficiency and economics. J Electrochem Soc 3:38.

18. Fukatsu K, KokotS (2000) Bleaching of Cotton Fabric by Electrogenerated Species-Decoloration of Coloring Matter by Electrolysis. Textile Research Journal 70(4): 340-346.

19. Jain R, Bhargava M, Sharma N (2003) Electrochemical studies on a pharmaceutical azo dye: Tartrazine. Ind Eng Chem res 42: 243.

20. JO’m B, Reddy AKN (1972) Modern electrochemistry. Plenum.

21. Brillas E, Martínez-Huitle CA (2015) Decontamination of wastewaters containing synthetic organic dyes by electrochemical methods. An updated review. Applied Catalysis B: Environmental 166-167: 603-643.

22. Jain $\mathrm{R}$ (2003) Treatment and decolorization of an azo dye in industrial effluent.

23. Trotman ER (1975) Dyeing and chemical technology of textile fibres. Griffin. 